\title{
Investigating the Interaction between Disability and Depressive Symptoms in the Era of Widespread Access to ART
}

\author{
Hellen Myezwa ${ }^{1 *}$, Jill Hanass-Hancock ${ }^{2}$, Nikolas Pautz ${ }^{1}$, Rulaine Smith ${ }^{1}$ and Bradley Carpenter ${ }^{2}$ \\ ${ }^{1}$ University of the Witwatersrand, Faculty of Health Sciences, Johannesburg, South Africa \\ ${ }^{2}$ Health Economics HIV and AIDS Research Division (HEARD), University of KwaZulu-Natal, South Africa
}

\begin{abstract}
Introduction: HIV has much comorbidity that includes depression. Additionally, disability has been found to manifest in HIV. However, the intersection between these co-morbidities is unknown. The primary aim is investigating the link between the onset of disability and depressive symptoms amongst a cohort of patients on antiretroviral treatment.
\end{abstract}

Materials and method: We conducted a cross sectional survey in an urban area of South Africa including measures for depressive symptoms, functional limitations/disability, adherence, HIV-related health symptoms, and livelihood. One thousand and fifty-five adult individuals ( $\geq 18$ years old) were recruited from Themba Lethu HIV clinic in Johannesburg between August 2014-May 2015. Bivariate and logistic regression analysis was used to determine associations.

Results: Participants experiencing depressive symptoms had higher functional limitations on all sub-categories expect for one. The logistic regression model revealed that having depressive symptoms as a bivariate dependent variable and age, physical health, and disability as independent variables were statistically significantly associated, $X^{2}$ $(3)=199.63, p<0.001$. The model explained $23.7 \%$ (Nagelkerke $\mathrm{R}^{2}$ ) of the variance in depressive symptom classification, with increases in age, physical health symptoms, and disability being associated with an increase in symptoms.

Conclusion: As reported in a related study functional limitations, age, and health symptoms were directly associated to an increase in depressive symptoms. Gender and ART adherence were not found to be significant contributing variables to depressive symptoms when controlling for other covariates (disability, age, physical health). Hence, the association between depressive symptoms, health, and disability is much more nuanced and complex than previously anticipated. Development of a comprehensive continuum of care needs to consider the importance of disability as both a driver of depression and an outcome. Rehabilitation interventions hold a key to addressing these new health-related needs now that people survive the acute stages of AIDS and can live a long life.

Keywords: Disability; Depression; HIV; Rehabilitation; Comorbidity; Suppression

\section{Introduction}

Within the last decade we have witnessed the transition of HIV into a chronic condition in South Africa due to the rapid roll-out of antiretroviral therapy (ART) [1]. A national and government-sponsored ART-programme in South Africa has resulted in increased survival rates among people living with HIV (PLHIV) and decreased morbidity $[2,3]$. However, this transition comes with new health-related needs linked to the chronicity of the disease that for many will span several decades of life [4-8].

Due to the transition from a fatal to chronic disease more attention is now being given to co-morbidities and factors that compromise adherence to ART. An early study [9] showed that $81 \%$ of patients who were $95 \%$ adherent to their medication regimen demonstrated viral suppression. This was in stark contrast with individuals who were only $80-90 \%$ adherent where only half demonstrated successful viral suppression. While early studies in Africa [10] showed great promise around ART adherence, recent literature is less promising and shows a decline of adherence to almost $20-40 \%$ in a five year period [11]. One of the factors associated to ART adherence is comorbid depression [12].

Depression and depressive symptoms are the most common psychiatric co-morbidity reported among PLHIV, with prevalence rates ranging from 25 to $36 \%$ [13]. Similar co-morbidities were found by Gonzalez and colleagues in their meta-analysis of 35,029 participants [14]. Depression is also said to have a gendered dimension, with women being 50 to 100 percent more likely to be depressed than men [15].

While ART reduces the risk of death and of developing serious opportunistic infections, there is some evidence which suggests that people living on long term ART face not only new health-related challenges including depressions but may also experience the onset of disability $[1,8,16,17]$. The disabling effects of living with chronic HIV have been linked to HIV itself, its comorbid conditions, and possible side effects of the medication regimen $[18,19]$. These may lead to a wide range of changes in body function, such as cognition, vision, hearing, and mental health. Two systematic reviews found that PLHIV of all ages in sub-Saharan Africa experience a diverse range of disabling conditions $[8,20]$.

*Corresponding author: Hellen Myezwa, Associate Professor, Head of Department, Department of Physiotherapy, University of the Witwatersrand, Faculty of Health Sciences, 7 York Road, Park town, Johannesburg, 2193, South Africa, Tel: +270117173721; Fax: 270865534769; E-mail: hellen.myezwa@wits.ac.za

Received May 07, 2016; Accepted May 27, 2016; Published June 04, 2016

Citation: Myezwa H, Hanass-Hancock J, Pautz N, Smith R, Carpenter B (2016) Investigating the Interaction between Disability and Depressive Symptoms in the Era of Widespread Access to ART. J AIDS Clin Res 7: 584. doi:10.4172/21556113.1000584

Copyright: ( 2016 Myezwa $\mathrm{H}$, et al. This is an open-access article distributed under the terms of the Creative Commons Attribution License, which permits unrestricted use, distribution, and reproduction in any medium, provided the original author and source are credited. 
Literature investigating disability commonly uses the International Classification of Function Disability and Health (ICF) [21] as a guiding tool. Within the ICF, disability is understood as "an umbrella term for impairments, activity limitations and participation restrictions. It denotes the negative aspects of the interaction between a person's health condition(s) and that individual's contextual factors (environmental and personal factors)" (WHO, p. 3). These ICF components and domains can be seen in Table 1 below.

Before ART rollout a high prevalence of concurrent impairments were reported, with an average of seven impairments and approximately one third of the sample experiencing more than ten impairments in the month prior to their assessment. Rusch et al. [22] reported that $80 \%$ of the cohort experienced activity limitations and participation restrictions. Limitations were also reported in another study using the ICF framework [23]. The results showed a high prevalence of physical impairments (sensory function, pain, and hypertension), participation restrictions (learning and applying knowledge, remunerative employment, and economic self-sufficiency), selective activity limitations (interpersonal relationships and interactions, and mobility), and that environmental factors (labour, employment, and legal housing services) had an influence on these individuals' level of ability.

There is little investigation with regards to the link of depression or depressive symptoms and disability in the growing number of people living with HIV who make use of ART. Generally, epidemiologists have predicted that depression will soon be the leading cause of disability throughout the world [24]. Research has also revealed that depressed patients report an increased level of impairment across physical and emotional domains, much greater than people with other chronic conditions [25]. Additionally, there is a growing body of evidence indicating that depression is associated with more rapid disease progression among HIV-positive individuals [26]. Within the context of ART rollout, the associations between depression, its symptoms, and disability have not yet been investigated in South Africa. However, considering the potential impact of comorbid depression or depressive symptoms and disability on ART adherence this is an urgent concern. Thus, the primary objective of this paper is to determine the scope of disability and depressive symptoms within the cohort and investigate the association between both.

\section{Method}

This study is one of the primary cross-sectional surveys that were part of a larger study (HIV-Live) to investigate the intersection of disability, health and livelihood in people who are on long-term
ART medication [5]. The survey included scales measuring activity limitations or disability with the WHODAS 2.0 [27], depressive symptoms with the CES-D 10 [28], HIV-related health symptoms [29], ART adherence with the Mannheimer adherence index [30], biomarkers (BMI, CD4), and livelihood outcomes using the HIV-Live study scales (Table 2) [31]. This paper reports on the primary cohort in a public health care setting in Johannesburg, South Africa.

\section{Participants and Recruitment}

One thousand and fifty-five adult individuals living with HIV ( $\geq$ 18 years old, 6 months and longer on ART) were recruited from large public health HIV clinic in Johannesburg between August 2014-May 2015.

Sample size and sampling - Using Stata 12: The formula for one sample comparison of proportions to hypothesized values (one sample size computation). Taking a power of $90 \%$ alpha of $5 \%$ two sided test. Our population was based on $50 \%$ and our sample is hypothesized $55 \%$. The sample size is 1050 . If powered at $80 \%$ the sample size is 967 therefore this study aimed for a sample of 1000 . As it was a cross sectional study participants were approached consecutively during their routine visit at the clinic. Trained interviewers conducted the survey after informed consent. Confidentiality of all information was assured through coding of the questionnaire. Participants were compensated for their travel costs. Ethical clearance was obtained from the human medical research and ethics committee University of the Witwatersrand (ethical clearance no M131187).

\section{Statistical Analysis}

Descriptive, correlational, and logistic regression analyses were conducted. The CES-D 10 was used as the dependent variable, with the WHODAS 2.0, age, adherence, and health symptoms scores acting as independent variables to determine the influence of these covariates on depression.

For the bivariate correlational analysis, Pearson's produce moment correlation coefficient was used to analyse the associations between the variables of age, gender, WHODAS 2.0 score, adherence score, BMI, CD4 cell count, livelihood, mental health and physical health with an alpha level of 0.05. A Binary Logistic Regression, using the backward Wald method, was used to further investigate the relationship between the variables found to be significant in the bivariate analysis with depressive symptoms. This allowed for a model based on significant outcomes to be generated; variables which were not significant and/or had high collinearity were excluded from the final model.

\begin{tabular}{|c|c|c|c|}
\hline Body Structure & Body Function & Activities and Participation & Environmental Factors \\
\hline Structure of the nervous system & Mental functions & Learning and applying knowledge & Products and technology \\
\hline The eye, ear and related structures & Sensory functions and pain & General tasks and demands & $\begin{array}{l}\text { Natural environment and human- } \\
\text { made changes to environment }\end{array}$ \\
\hline Structures involved in voice and speech & Voice and speech functions & Communication & Support and relationships \\
\hline $\begin{array}{l}\text { Structure of the cardiovascular, immunological and } \\
\text { respiratory Systems }\end{array}$ & $\begin{array}{l}\text { Functions of the cardiovascular, } \\
\text { haematological, immunological and } \\
\text { respiratory systems }\end{array}$ & Mobility & Attitudes \\
\hline $\begin{array}{l}\text { Structures related to the digestive, metabolic and } \\
\text { endocrine systems }\end{array}$ & $\begin{array}{l}\text { Functions of the digestive, } \\
\text { metabolic, endocrine systems }\end{array}$ & Self-care & Services, systems and policies \\
\hline $\begin{array}{l}\text { Structure related to genitourinary and reproductive } \\
\text { systems }\end{array}$ & $\begin{array}{l}\text { Genitourinary and reproductive } \\
\text { functions }\end{array}$ & Domestic life & \\
\hline Structures related to movement & $\begin{array}{l}\text { Neuromusculoskeletal and } \\
\text { movement-related functions }\end{array}$ & $\begin{array}{l}\text { Interpersonal interactions and } \\
\text { relationships }\end{array}$ & \\
\hline Skin and related structures & $\begin{array}{l}\text { Functions of the skin and related } \\
\text { structures }\end{array}$ & $\begin{array}{c}\text { Major life areas } \\
\text { Community, social and civic life }\end{array}$ & \\
\hline
\end{tabular}

Table 1: Components and domains of the International Classification of Function Disability and Health [21]. 
Citation: Myezwa H, Hanass-Hancock J, Pautz N, Smith R, Carpenter B (2016) Investigating the Interaction between Disability and Depressive Symptoms in the Era of Widespread Access to ART. J AIDS Clin Res 7: 584. doi:10.4172/2155-6113.1000584

Page 3 of 7

\begin{tabular}{|c|c|c|c|c|}
\hline $\begin{array}{l}\text { Element } \\
\text { measured }\end{array}$ & Tool & Variables & Source & Data analysis \\
\hline $\begin{array}{c}\text { Socio- } \\
\text { demographic }\end{array}$ & $\begin{array}{l}\text { Socio- } \\
\text { demographic } \\
\text { questionnaire }\end{array}$ & $\begin{array}{l}\text { Age gender and marital status (*other factors are indicated in } \\
\text { the livelihoods section) }\end{array}$ & - & Descriptive and correlations \\
\hline Livelihood & $\begin{array}{l}\text { HIV-Live } \\
\text { livelihood } \\
\text { capitals (self- } \\
\text { developed from } \\
\text { literature) }\end{array}$ & $\begin{array}{l}\text { Education, financial capital, including source of income, } \\
\text { physical and natural capital including housing, source of } \\
\text { income, water and sanitation, social capital and food security }\end{array}$ & $\begin{array}{l}\text { (Hanass- } \\
\text { Hancock et al., } \\
\text { In press) }\end{array}$ & Descriptive \\
\hline $\begin{array}{l}\text { Medical } \\
\text { history }\end{array}$ & $\begin{array}{l}\text { Medical } \\
\text { symptoms } \\
\text { questionnaire }\end{array}$ & $\begin{array}{l}\text { Confusion, Memory loss, Breathlessness, Fatigue, Diarrhea, } \\
\text { Nausea, Stomach Pain, Headache, Change in taste, Change } \\
\text { in taste, Skin itching/changes. Muscular pain, Heartburn, } \\
\text { Sore mouth, Vomiting, Fever, Kidney stones. Included in this } \\
\text { section were the patient weight height, CD4 count }\end{array}$ & $\begin{array}{l}\text { (Duran et al., } \\
\text { 2001) }\end{array}$ & $\begin{array}{l}\text { Overall score converted to a metric of } 0-100 \% \text {. Where } \\
100=\text { full health and } 0 \text { experiencing all symptoms. }\end{array}$ \\
\hline $\begin{array}{l}\text { Physical and } \\
\text { functional } \\
\text { health }\end{array}$ & $\begin{array}{l}\text { WHODAS } 2.0 \\
\text { (5 point likert } \\
\text { scale) }\end{array}$ & $\begin{array}{l}\text { Mobility (standing and walking), Self-care (washing, getting } \\
\text { dressed), Participation (involvement in life situations), } \\
\text { Cognition (learning concentration and memory),getting along } \\
\text { (dealing with people and maintaining friendship)and life } \\
\text { activities (work and education) }\end{array}$ & $\begin{array}{l}\text { Validity and } \\
\text { reliability } \\
\text { (Nyirenda et } \\
\text { al., 2012) }\end{array}$ & $\begin{array}{l}\text { WHO item response theory-scoring and data analysis } \\
\text { system. } \\
\text { Analysis uses overall weighted score of } 3636=\text { lowest } \\
\text { level of function. A converted summary score is } \\
\text { calculated with a metric of } 0-100 \text {. (100 is equal to full } \\
\text { functioning and } 0 \text { depicts severe dysfunction) }\end{array}$ \\
\hline Mental health & $\begin{array}{l}\text { CESD-10 (4 } \\
\text { point Likert } \\
\text { scale) }\end{array}$ & $\begin{array}{l}\text { Comprises ten questions prompting Status as far as } \\
\text { depression, level of bother, how fearful, hopeful, happy or } \\
\text { lonely one is and the effort required to get going. }\end{array}$ & $\begin{array}{l}\text { (Myer et al., } \\
\text { 2008) }\end{array}$ & $\begin{array}{c}\text { A sum of the scores was taken and a cut off of } 16 \\
\text { and above was considered at risk of depression. A } \\
\text { converted summary score is calculated with a metric of } \\
0-100 \text { (100 is equal to no symptoms of depression and } \\
0 \text { depicts severe symptoms of depression). }\end{array}$ \\
\hline
\end{tabular}

Table 2: HIV-live study scales.

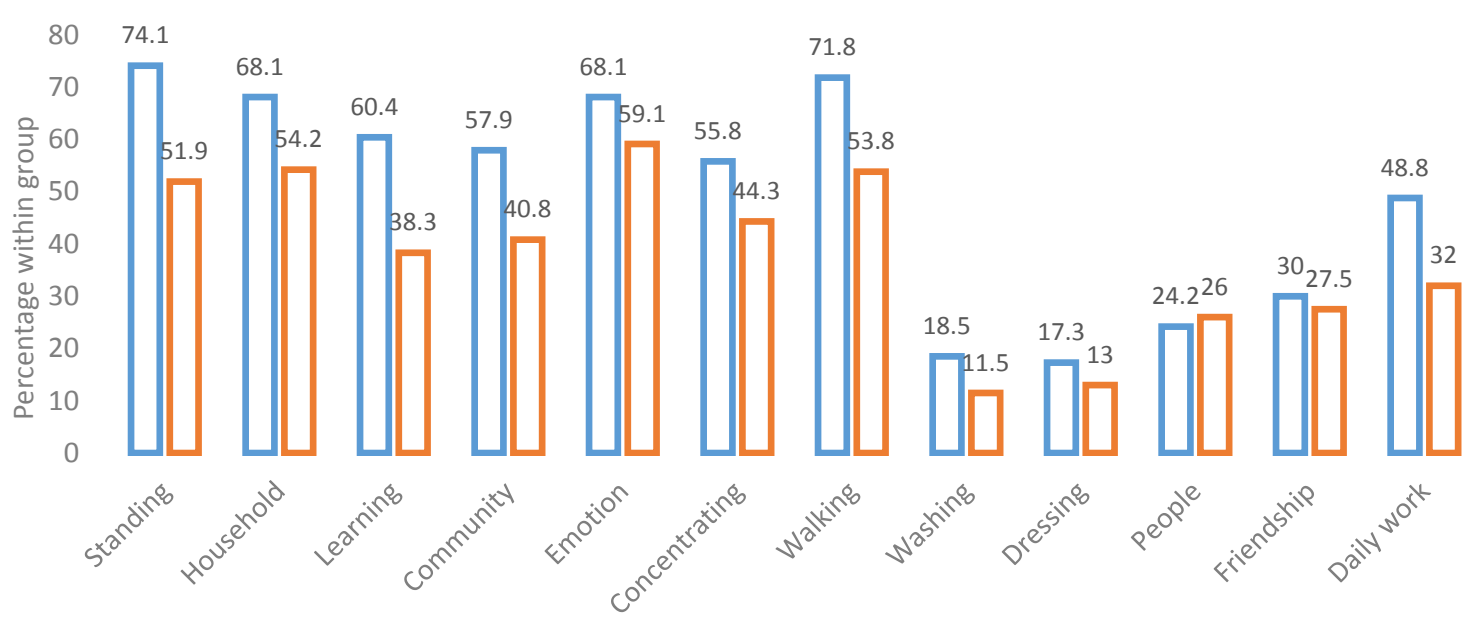

믈 $10>10$ ㄷSD10 < 10

Figure 1: WHODAS 2.0 functional limitations within the cohort who scored 2 or greater on the WHODAS scale.

The sample was also divided into two groups: those who experience depressive symptoms (EDS) (CES-D10, scoring 10 or more) and those with no depressive symptoms (NDS) (under 10) [28]. An independent samples t-test was used to compare the responses of the CESD-10 against the participant's WHODAS 2.0 score. It must be noted that there were some missing data in the dataset, however, the models and calculations used in the analyses accounted and allowed for missing data once it was categorized as such.

\section{Results}

Almost half $(45.7 \%)$ of the sample scored two or more on the WHODAS2.0 weighted score indicating the development of functional limitations and onset of disability. Over $60 \%(60.8 \%)$ of the sample scored 10 or more on the CESD-10 indicating the experience of depressive symptoms. There was some gender disparity with regards to depressive symptoms, with $54.9 \%$ of males and $63 \%$ of females displaying depressive symptoms compared to $25.2 \%$ of males and $74.8 \%$ of females displaying depressive symptoms. Both genders experienced similar distributions of relationship status, with $27.1 \%$ of the NSD group being married at the time of data collection, as opposed to only $22 \%$ of the EDS group. In the NSD group, $67.4 \%$ of the individuals earned an income, whilst only half $(50.38 \%)$ of the ESD group earned an income (Table 3).

The survey also revealed a diverse experience of functional limitations with scores in all domains (mobility, life functionality, cognition, participation in social activities, self-care and getting along with other; WHODAS). Figure 1 illustrates the percentage of participants who scored two or more on the WHODAS 2.0. The figure also illustrates higher percentages of participants who experienced functional limitations in the group with depressive symptoms than in the one without (Figure 1).

There was a statistically significant difference between the 
Citation: Myezwa H, Hanass-Hancock J, Pautz N, Smith R, Carpenter B (2016) Investigating the Interaction between Disability and Depressive Symptoms in the Era of Widespread Access to ART. J AIDS Clin Res 7: 584. doi:10.4172/2155-6113.1000584

Page 4 of 7

\begin{tabular}{|c|c|c|c|}
\hline \multirow[t]{2}{*}{ Characteristics } & Whole Cohort & $\begin{array}{c}\text { People CESD10 0<10 } \\
\text { NDS group }\end{array}$ & $\begin{array}{c}\text { People CESD10>10 } \\
\text { EDS group }\end{array}$ \\
\hline & $(n=1055)$ & $(n=413)$ & $(n=642)$ \\
\hline Age, mean ( \pm SD) & $41.8(8.24)$ & $40.61(8.21)$ & $42.58(8.17)$ \\
\hline \multicolumn{4}{|l|}{ Gender, n (\%) } \\
\hline Men & $293(27.8)$ & $132(32)$ & $161(25.2)$ \\
\hline Women & $759(72.1)$ & $281(68)$ & $478(74.8)$ \\
\hline \multicolumn{4}{|l|}{ Marital Status, n (\%) } \\
\hline Never married, single & $517(49)$ & $193(46.6)$ & $324(50.5)$ \\
\hline Currently married & $253(24)$ & $112(27.1)$ & $141(22)$ \\
\hline Divorced, Separated or Widowed & $211(20)$ & $79(19.08)$ & $132(20.59)$ \\
\hline Cohabiting & $74(7)$ & $30(7.2)$ & $44(6.9)$ \\
\hline \multicolumn{4}{|l|}{ Education status, $\mathbf{n}(\%)$} \\
\hline No formal schooling & $17(1.6)$ & $5(1.2)$ & $12(1.9)$ \\
\hline Some primary/primary completed & $144(13.6)$ & $54(13)$ & $90(14)$ \\
\hline High school & $778(73.8)$ & $286(69.1)$ & $492(76.7) 1$ \\
\hline Post-secondary & $114(10.81)$ & $68(16.42)$ & $47(7.33)$ \\
\hline Refused/don't know & $1(0.1)$ & n.a. & $1(0.2)$ \\
\hline \multicolumn{4}{|l|}{ Source of Income, $n(\%)$} \\
\hline Earned Income & $610(58.43)$ & $277(67.4)$ & $333(50.38)$ \\
\hline Gifts & $7(0.7)$ & $1(0.2)$ & $6(0.9)$ \\
\hline Disability Grant & $14(1.3)$ & $3(0.7)$ & $11(1.7)$ \\
\hline Other Grants & $77(7.3)$ & $21(5.1)$ & $56(8.7)$ \\
\hline Other Income & $94(8.9)$ & $26(6.3)$ & $68(10.6)$ \\
\hline No Income & $44(4.2)$ & $15(3.6)$ & $29(4.5)$ \\
\hline Don't Know & $196(18.6)$ & $66(15.9)$ & $130(20.3)$ \\
\hline Refused & $2(0.2)$ & $2(0.5)$ & n.a. \\
\hline Income, mean ( \pm SD) (R) & $5252.322(5443.87)$ & $6749.47(5860.13)$ & 4242.31 (4897.11) \\
\hline WHODAS weighted score, & \multirow{2}{*}{$4.34(6.15)$} & \multirow{2}{*}{$2.26(3.99)$} & \multirow{2}{*}{$5.7(6.9)$} \\
\hline mean out of $36( \pm \mathrm{SD})$ & & & \\
\hline CES-10 Score, mean out of 40 ( \pm SD) & $11.84(6.75)$ & $5.3(2.8)$ & $16.06(4.96)$ \\
\hline Adherence Score, & \multirow{2}{*}{$14.38(2.73)$} & \multirow{2}{*}{$14.35(2.66)$} & \multirow{2}{*}{$14.39(2.78)$} \\
\hline mean out of $16( \pm S D)$ & & & \\
\hline Years Living with HIV ( \pm SD) & $7.6(4.4)$ & $7.47(4.39)$ & $7.67(4.41)$ \\
\hline Years on ART & $6.88(3.57)$ & $6.66(3.39)$ & $7.02(3.67)$ \\
\hline Health Symptoms, mean out of 16 ( \pm SD) & $5.19(3.45)$ & $3.67(2.92)$ & $6.17(3.41)$ \\
\hline BMI, & \multirow{2}{*}{$26.12(6.30)$} & \multirow{2}{*}{$26.38(6.21)$} & \multirow{2}{*}{$25.95(6.36)$} \\
\hline mean $( \pm \mathrm{SD})$ & & & \\
\hline CD4 Count, mean ( \pm SD) & $395.46(263.42)$ & $389.49(269.72)$ & $399.28(259.47)$ \\
\hline
\end{tabular}

$\mathrm{R}=$ South African Rand

Table 3: Overall cohort socio-demographics.

WHODAS score for the NDS group $(M=5.46, \mathrm{SD}=4.37)$ and EDS group $(M=9.76, \mathrm{SD}=6.63) ; t(-7.63)=531, p<0.001$.

Depressive symptoms were associated with health symptoms $(r=0.412)$, functional limitations $(r=0.272)$, age $(r=0.146)$, and gender $(r=0.109)$ but not with clinical outcomes such as BMI $(r=0.001)$ or CD4 count $(r=0.056)$. Hence, people with more health symptoms, higher functional limitations, older age, and female gender are more likely to experience depressive symptoms. ART adherence was not associated to depressive symptoms but was associated to functional limitations $(r=-0.133)$, with lower adherence scores being more likely with higher functional limitations scores.

The bivariate analysis suggested that gender, age, health symptoms, and functional limitations predicted depressive symptoms. We used a logistic regression model (Table 4) to further investigate the effects of age, gender, level of ART adherence, WHODAS2.0 weighted disability score, and the health symptoms on outcomes for depressive symptoms. Gender

\begin{tabular}{|c|c|}
\hline Variable & Mental health $\mathbf{r}(\mathbf{p}$ value $)$ \\
\hline Age & $0.146(0.001)$ \\
\hline Gender & $0.109(0.001)$ \\
\hline Physical Health & $0.412(0.001)$ \\
\hline WHODAS 2.0 Score & $0.272(0.001)$ \\
\hline Adherence Score & $0.015(0.637)$ \\
\hline BMI & $0.001(0.987)$ \\
\hline CD4 Cell Count & $0.056(0.08)$ \\
\hline
\end{tabular}

Table 4: Associations between mental health and other variables.

and adherence score were initially included as independent variables, but were not significant using the model $(p=0.866 ; p=0.313)$ and were therefore excluded from the final model under the Wald criterion. The logistic regression model was statistically significant, $\chi^{2}(3)=199.63, p<0.001$. The model explained $23.7 \%$ (Nagelkerke $\mathrm{R}^{2}$ ) of the variance in depressive symptom classification, indicating a moderate relationship between prediction and grouping. Prediction success overall was $69.1 \%$ (Table 5). 


\begin{tabular}{|c|c|c|c|c|c|c|c|c|}
\hline \multirow[b]{2}{*}{ Variable } & \multirow[b]{2}{*}{ B } & \multirow[b]{2}{*}{ S.E. } & \multirow[b]{2}{*}{ Wald } & \multirow[b]{2}{*}{ df } & \multirow[b]{2}{*}{ Sig. } & \multirow[b]{2}{*}{$\operatorname{Exp}(B)$} & \multicolumn{2}{|c|}{$\operatorname{Exp}(\mathrm{B}) 95 \% \mathrm{Cl}$} \\
\hline & & & & & & & Lower & Upper \\
\hline Age & 0.027 & 0.009 & 9.81 & 1 & 0.002 & 1.027 & 1.01 & 1.05 \\
\hline Total Health Symptoms & 0.22 & 0.023 & 89.83 & 1 & 0.001 & 1.25 & 1.19 & 1.305 \\
\hline WHODAS Weighted Score & 0.088 & 0.014 & 36.95 & 1 & 0.001 & 1.092 & 1.061 & 1.123 \\
\hline
\end{tabular}

Table 5: Logistic regression table for depressive symptoms.

From the model, only age, total health symptoms, and WHODAS weighted score remained as significant factors associated with depressive symptoms.

\section{Discussion}

We have investigated the link between depressive symptoms (CESD10) and functional limitations/disability (WHODAS 2.0) in people living on long-term ART medication. The majority of participants experienced at least one functional limitation, further substantiating the findings from previous studies [1,5-8,16,17,23,31]. Participants who experienced depressive symptoms had higher levels of functional limitations, mirroring the findings from its sister study in a semi-rural area [5].

Disability literature has already established a close link between the experience of disability and depression [21]. Results from our study support the notion of a triple burden of health-related needs in people living with HIV and on long term ART, relating specifically to functional limitations/disability, depressive symptoms, and HIVrelated comorbidities. The direction of the association is complex in that the effect of functional disability on depressive symptoms can be bidirectional; i.e. functional limitations can be driven by depressive symptoms or other socio-economic drivers, or depressive symptoms can change the way we function.

Our model revealed that the strongest predictors of depressive symptoms were health symptoms, followed by disability. It is well established that medical conditions increase the risk of disability, which in turn may influence the depression status of an individual. However, disability can also influence health seeking behaviour, hence increasing health disparities and the risk of depression [32]. Our model found that increased health conditions and functional limitations as well as older age were predictors of depressive symptoms; however the directionality of these associations is still unclear. In addition, the literature reveals a close link between these predictors and the risks of poverty and reduced quality of life, a finding supported by our sister study [33].

Further research needs to examine these associations while accounting for the complexity of the triple burden and its impact on HIV outcomes such as ART adherence, health outcomes, and livelihoods. Considering the high incidence of disability and depressive symptoms in both of our studies we also need to understand how health care and social services can mitigate both [5].

The results of this research corroborate Nomoto et al's [13] findings, with the majority (61\%) of the sample of PLHIV experiencing depressive symptoms. Additionally, while not as extreme as that reported by Gonzalez et al. [14], the results suggest a gendered dimension influencing the experience of depressive symptoms, with approximately $63 \%$ of woman being depressed, compared to $55 \%$ of men.

Our findings also support those reported by Rusch et al. [22] and Katon [32]. We found that, on average, participants experienced several physical health problems at the time of data collection, with participants in the EDS group experiencing significantly more physical health problems than those in the NDS group. Lastly, our findings supported the results of previous research with regards to disability and depressive symptoms or depression $[5,23,25]$. In every sub-domain of the WHODAS (with the exception of "getting along with people") participants who experienced depressive symptoms also reported more pronounced functional limitations.

In contrast to the findings reported by Beusterien et al. [12] as well as our sister study [5] which both suggested that adherence and comorbid depression or depressive symptoms are correlated, we found no such association in this study. The reason that other variables, such as socioeconomic or livelihood outcomes, which intersect with depressive symptoms (as illustrated by the bivariate correlation) were not included in the mode is because they did not alter the odds of an individual displaying depressive symptoms [34,35]. Additionally, we found no evidence that depressive symptoms were associated with time since first HIV diagnosis [26], however, the difference in health symptoms between the two groups suggests that there could still be a link. It is important to note, though, that the average participant in this study had been living with HIV for approximately seven and a half years and had been on ART for approximately seven years before participating in this study. This length of time may have had an influence on the outcome of the results due to the association between time on ART and depressive symptoms.

Considering the high incidence of depressive and health-related symptoms, the onset of disability indicated in this sample, and its potential impact on treatment adherence and livelihoods, we need to consider how a continuum of care can cater for these new healthrelated needs of people on long term ART.

The National Mental Health Policy Framework and Strategic Plan (2013-2020) recognise that the relationship between mental illness and HIV is complex, in that both conditions are exacerbated and negatively impact each other [34]. Thus, the framework challenges the mental health service delivery platform to ensure that both community and district based models are developed and implemented to meet the needs for all mental health care users, especially those who have complex comorbid diagnoses.

The UN Strategy for HIV, in target 11 and 19, refers to enabling and funding community based responses in key priority populations [36]. A manifestation of depressive symptoms and disability in the HIV disease profile calls for a shift in our thinking that includes rehabilitation approaches within HIV treatment, care, and support. An increased level of support from governmental and non-governmental organisations is needed to change policy and practice in order to accommodate the needs arising from living with chronic HIV. PLHIV require access to treatment programmes which can mitigate the impact of both disability and depressive symptoms.

Thus, there is a need to include disability in health priority programmes and research. The South African policy and programme documents has recently acknowledged this need [34,37]. Similarly, the countries National Strategic Plan on HIV (2012-2016) [38] includes, in Objective three, the goal to promote wellness and prevent coinfections such as TB or disability. However, there are no implementation 
recommendations or targets within the NSP and its operational plan on how to mitigate disability. More recently, South Africa has released its new Framework on disability and rehabilitation, which includes a section on HIV. While South Africa is reviewing its state of readiness to implement this framework, it needs to consider how it can cater for the millions of people already living with HIV who may be at risk of developing disabilities and depression.

Within the wider Southern African region UNAIDS sets, with its ambitious targets in the HIV Fast Tracking Strategy (90:90:90) [39], goals for 2030 that will not be achieved without including disability in the continuum of care as disability holds the risk of impacting health seeking behaviour, adherence to ART and livelihoods.

\section{Conclusion}

A growing body of evidence suggests that depression, depressive symptoms, functional limitations, and disability are linked to living with chronic HIV. Our work highlights the additional link between depressive symptoms and disability, both of which have the potential to affect the outcomes of living with chronic HIV negatively. In addition, it reaffirms that older age and increased health symptoms are linked to disability. In contrast to previous research, when included in the regression model, gender and ART adherence were not found to be significant contributing variables to depressive symptoms when other covariates (disability, age, physical health) were taken into account. This indicates that as people grow older and live longer with HIV the need for rehabilitative services to mitigate both depressive symptoms and the onset of disability increases.

It is likely that there is two-pronged path regarding the link between depressive symptoms and disability. The experience of disability has a debilitating effect on an individual's ability to manage their social and professional life, lowers their ability to actively participate in society as well as their ability to work. This has a far reaching impact on the individual's socio-economic status and ability to cope, but also on the wider society through its potential impact on ART adherence and economic growth. While this research study only used a cohort of people on long term ART, the measured experience of functional limitations is with around $50 \%$ of the sample much higher than the prevalence of disability measured with the last South African census (7.5\%, 2011). Although the two data sets use two different measures (WHODAS 2.0 and Washington set of questions) we assume that the prevalence in our sample is still disproportionally high and further research is needed to better understand and measure disability within populations on ART in Africa. In order to better understand this link we need both disability focused and disability mainstreamed research. Thus, research focusing on health priorities such as adherence to ART, the ideal continuum of care for people living with HIV, and comorbidities need to include disability within their research design. Such research will provide us with a better understanding of the prevalence and impact of disability on priority health programmes, the scope and types of disabilities experienced by people living with chronic HIV, and their needs for rehabilitation.

\section{Limitations}

The results of this study provide information on the risk of depression through a well powered study. The nature of the study design cannot provide information on direction of causality. The very nature of disability is complex and has multidirectional relationships with other factors. As such, there is need for further qualitative research to understand the more explorative questions that emerge.

\section{References}

1. Myezwa H, Stewart A, Musenge E, Nesara P (2009) Assessment of HIV-positive in-patients using the International Classification of Functioning, Disability and Health (ICF), at Chris Hani Baragwanath Hospital Johannesburg. African Journal of AIDS research 8: 93-106.

2. Bor J, Herbst AJ, Newell ML, Bärnighausen T (2013) Increases in adult life expectancy in rural South Africa: Valuing the scale-up of HIV treatment Science 339: 961-965.

3. Global. UNAIDS: Access to HIV therapy tripled in 2 years (2006) AIDS Policy Law 21: 1, 4

4. Deeks SG, Lewin SR, Havlir DV (2013) The end of AIDS: HIV infection as a chronic disease. Lancet 382: 1525-1533.

5. Hanass-Hancock J, Myezwa H, Carpenter B (2015) Disability and Living with HIV: Baseline from a cohort of people on long term ART in South Africa. PLoS One 10: e0143936

6. Hanass-Hancock J, Myezwa H, Nixon S, Gibbs A (2015) "When I was no longer able to see and walk, that is when I was affected most": Experiences of disability in people living with HIV in South Africa. Disability and Rehabilitation. Early online 1-11.

7. Hanass-Hancock J, Nixon S (2009) The fields of HIV and disability: Past present and future. Journal of the International AIDS Society 12: 28.

8. Hanass-Hancock J, Regondi I, Van Egeraat L, Nixon S (2013) HIV-related disability in HIV hyper-endemic countries: A scoping review. World Journal of AIDS 3: 257-279.

9. Stephenson J (1999) AIDS researchers target poor adherence. JAMA 281: 1069.

10. Mills E, Nachega J, Buchan I, Orbinski J, Attaran A, et al. (2006) Adherence to antiretroviral therapy in sub-Saharan Africa and North America. Journal of the American Medical Association 296: 679-690.

11. Fox M, Rosen S (2013) Retention on antiretroviral therapy in low- and middleincome countries: Systematic Review of Papers and Abstracts Since 2008 Boston University, Boston.

12. Beusterien KM, Davis EA, Flood R, Howard K, Jordan J (2008) HIV patient insight on adhering to medication: A qualitative analysis. AIDS Care 20: 244-252.

13. Nomoto SH, Longhi RMP, de Barros BP, Croda J, Ziff EB, et al. (2015) Socio-economic disadvantage increasing risk for depression among recently diagnosed HIV patients in an urban area in Brazil: Cross-sectional study. AIDS Care 27: 979-985

14. Gonzalez JS, Batchelder AW, Psaros C, Safren SA (2011) Depression and HIVIAIDS treatment non-adherence: $A$ review and meta-analysis. Journal of acquired immune deficiency syndromes 58: 181-187.

15. Gore-Felton C, Koopman C, Spiegel D, Vosvick M, Brondino M, et al. (2006) Effects of quality of life and coping on depression among adults living with HIV/ AIDS. Journal of Health Psychology 11: 711-729.

16. Banks LM, Zuurmond M, Ferrand R, Kuper $\mathrm{H}$ (2015) The relationship between HIV and prevalence of disabilities in sub-Saharan Africa: Systematic review (FA). Tropical Medicine and International Health 20: 411-429.

17. Myezwa H, Buchalla CM, Jelsma J, Stewart A (2011) HIVIAIDS: Use of the ICF in Brazil and South Africa--comparative data from four cross-sectional studies. Physiotherapy 97: 17-25

18. Meintjes G, Maartens G, Boulle A (2012) Guidelines for antiretroviral therapy in adults. South African Journal of HIV Medicine 13: 114-131.

19. Nixon S, Hanass-Hancock J, Whiteside A, Barnett T (2011) The increasing chronicity of HIV in sub-saharan Africa: Re-thinking "HIV as a long-wave event" in the era of widespread access to ART. Globalisation and Health 7: 41.

20. Banks LM, Zuurmond M, Ferrand R, Kuper H (2015) The relationship between HIV and prevalence of disabilities in sub-Saharan Africa: Systematic review (FA). Trop Med Int Health 20: 411-429.

21. World Health Organization (2001) International classification of functioning disability and health.

22. Rusch M, Nixon S, Schilder A, Braitstein P, Chan K, et al. (2004) Impairments activity limitations and participation restrictions: Prevalence and associations among persons living with HIVIAIDS in British Columbia. Health and Quality of Life Outcomes 2: 1-10. 
Citation: Myezwa H, Hanass-Hancock J, Pautz N, Smith R, Carpenter B (2016) Investigating the Interaction between Disability and Depressive Symptoms in the Era of Widespread Access to ART. J AIDS Clin Res 7: 584. doi:10.4172/2155-6113.1000584

23. Van As M, Myezwa H, Stewart A, Maleka D, Musenge E (2009) The international classification of function disability and health (ICF) in adults visiting the HIV outpatient clinic at a regional hospital in Johannesburg, South Africa. AIDS Care 21: 50-58.

24. Depression: A Global Crisis (2012) World Federation for Mental Health.

25. Wells KB, Stewart A, Hays RD, Burnam MA, Rogers W, et al. (1989) The functioning and well-being of depressed patients: Results from the medical outcomes study. JAMA 262: 914-919.

26. Mayne TJ, Vittinghoff E, Chesney MA, Barrett DC, Coates TJ (1996) Depressive affect and survival among gay and bisexual men infected with HIV. Archives of Internal Medicine 156: 2233-2238

27. Ustün TB, Chatterji S, Kostanjsek N, Rehm J, Kennedy C, et al. (2010) Developing the World Health Organization Disability Assessment Schedule 2.0. Bull World Health Organ 88: 815-823.

28. Zhang W, O'Brien N, Forrest JI, Salters KA, Patterson TL, et al. (2012) Validating a shortened depression scale (10 item CES-D) among HIV-positive people in British Columbia, Canada. PloS One 7: e40793.

29. Duran S, Spire B, Raffi F, Walter V, Bouhour D, et al. (2001) Self-reported symptoms after initiation of a protease inhibitor in HIV-infected patients and their impact on adherence to HAART. HIV Clinical Trials 2: 38-45.
30. Mannheimer S, Thackeray L, Huppler Hullsiek K, Gardner EM, Wu Aw, et al. (2008) A randomized comparison of two instruments for measuring selfreported antiretroviral adherence. AIDS Care 20: 161-169.

31. Hanass-Hancock J, Misselhorn A, Myezwa H, Carpenter B (2016a) Determinants of livelihood in the era of widespread access to ART. AIDS Care.

32. Katon WJ (2003) Clinical and health services relationships between major depression, depressive symptoms and general medical illness. Biological psychiatry $54: 216-226$.

33. Jill Hanass-Hancock AM, Carpenter B, Myezwa H (2016b) Determinants of livelihood in the era of widespread access to ART. In Press.

34. National Mental Health Policy Framework and Strategic Plan 2013-2020 (2013) Department of Health SA.

35. Patel V (2001) Poverty inequality and mental health in developing countries.

36. UNAIDS (2016) UNAIDS Strategy 2016-2021.

37. UNAIDS (2015) Framework for the inclusion of disability in the national strategic plans on HIV and AIDS.

38. National Strategic Plan on HIV, STIs and TB 2012-2016 (2012) Council SANA. 39. Fast-Track—ending the AIDS epidemic by 2030 (2014) UNAIDS. 